\title{
Innovative Learning Environments, Are They Inclusive? Why Evaluating the Speaking, and Acoustic Potential of the Space Matters
}

\author{
Leanne Rose-Munro
}

\begin{abstract}
Innovative learning spaces are a platform primarily designed to support the activity of speaking, listening and learning. However, evidence suggests that nearly $10 \%$ of students attending mainstream schools in their local communities have hearing difficulties. This study explores the acoustic potential of innovative learning spaces (ILE's), and the impact of design affordances in terms of supporting the inclusion of students with hearing difficulties. The study highlights the importance of an acoustic platform that enables opportunity for all to participate in speaking and listening activity. In addition, the importance of student agency, the power to act and contribute to decision-making regarding the use and application of environmental affordances to enable student opportunity, inclusion and successful learning.
\end{abstract}

\section{The Innovative Learning Environment}

Innovative learning environments (ILEs) are speaking and listening spaces, a platform for student and teacher collaboration, creativity, complex problem solving and digital information gathering and sharing. Such learning spaces are auditory verbal environments where the primary information exchange occurs through speaking and listening activities (Munro, 2011). In designing innovative spaces there must be confidence that they are fit-for-purpose, account for diversity and ensure that speaking, listening and communication is accessible. The design principles of innovative learning spaces must enable the inclusion of all students and in particular a postulated 7-10\% of students with suboptimal hearing abilities.

A shift away from traditional school design towards ILEs commenced in Australia between 2008 and 2012, when a government initiative known as Building the Education Revolution provided funding, predominantly junior schools, to build new learning spaces. Numerous new schools, particularly in the state of Victoria, were designed as technology enhanced learning environments consisting of a series of open-plan visually connected spaces with semi-connected 'breakout' areas. The

L. Rose-Munro ( $\square)$

The University of Melbourne, Melbourne, Australia

e-mail: Learningspacesau@gmail.com

W. Imms and T. Kvan (eds.), Teacher Transition into Innovative Learning Environments, https://doi.org/10.1007/978-981-15-7497-9_13 
spaces were designed to inspire student-centred active learning pursuits. Such pedagogical approaches value student collaboration and participation in socially oriented learning and twenty-first-century skill development. Figure 1 is an example of an Innovative learning environment (ILE) built during the BER 2008-2012.

\section{The Problem}

While an increasing body of research is exploring how teachers and students use such spaces, a gap exists in research that defines how these innovative environments include a broad range of students including those with speech and language delay, auditory processing disorders, hearing loss and noise sensitivity such as those with autism. The scale of students with hearing difficulties in mainstream education is demonstrated by Australian Hearing, a statutory authority constituted under the Australian Hearing Services Act 1999. At the time of this study services were provided to 68,296 eligible children and young Australians with hearing loss during 2012-2013 (Australian Hearing, 2013). There is significant evidence to suggests ILE's should be designed with high acoustic performance as a priority given that an overwhelming majority of these students attend mainstream schools in their local communities (Byrnes, 2011; Vosganoff, Paatsch, \& Toe, 2011).

Listening in noise is a barrier to participating in conversation for many people, however of great concern is that research also indicates that students for whom English is an additional language, and those with speech and language difficulties, learning difficulties, cognitive disorders, attention disorders and behavioural problems also have difficulties listening and interpreting speech in noisy learning spaces (Massie \& Dillon, 2006; Rowe \& Pollard, 2003; Sharma, Purdy, \& Kelly, 2009; Shield, Greenland, \& Dockrell, 2010; Smaldino \& Flexer, 2012; Snow \& Powell, 2008). It is also widely reported that noisy environments adversely affect students with sensory disorders such as autism and vision loss by impacting cognition, heightening anxiety and diminishing access to clear speech (Anderson, 2001; Clark \& Sorqvist, 2012; Guardino \& Antia, 2012; Katte, Bergstroem, \& Lachmann, 2013; Smaldino \& Flexer, 2012). Collectively for the purpose of this research this cohort is referred to as students with hearing difficulties.

The study of acoustics, defined as the properties or qualities of a room or building that determine how sound is transmitted in it, have highlighted detrimental effects of noisy 'classrooms' on learning (Shield et al., 2010). Little is known about noise and acoustics in ILEs, as the interrelationships of pedagogy, innovative spatial design and technology are not yet broadly investigated and reported, and in particular how these elements play a role in creating new experiences for students with hearing difficulties (Brown \& Eisenhardt, 1997; Glaser \& Strauss, 1967; Spencer \& Marschark, 2010).

Communication modalities between the inhabitants of learning spaces has changed significantly overtime due to the embedded use of technology in educational settings. Furthermore, advances in design and construction materials such as acoustic attenuation, speech reinforcement systems and mobile device use challenge 

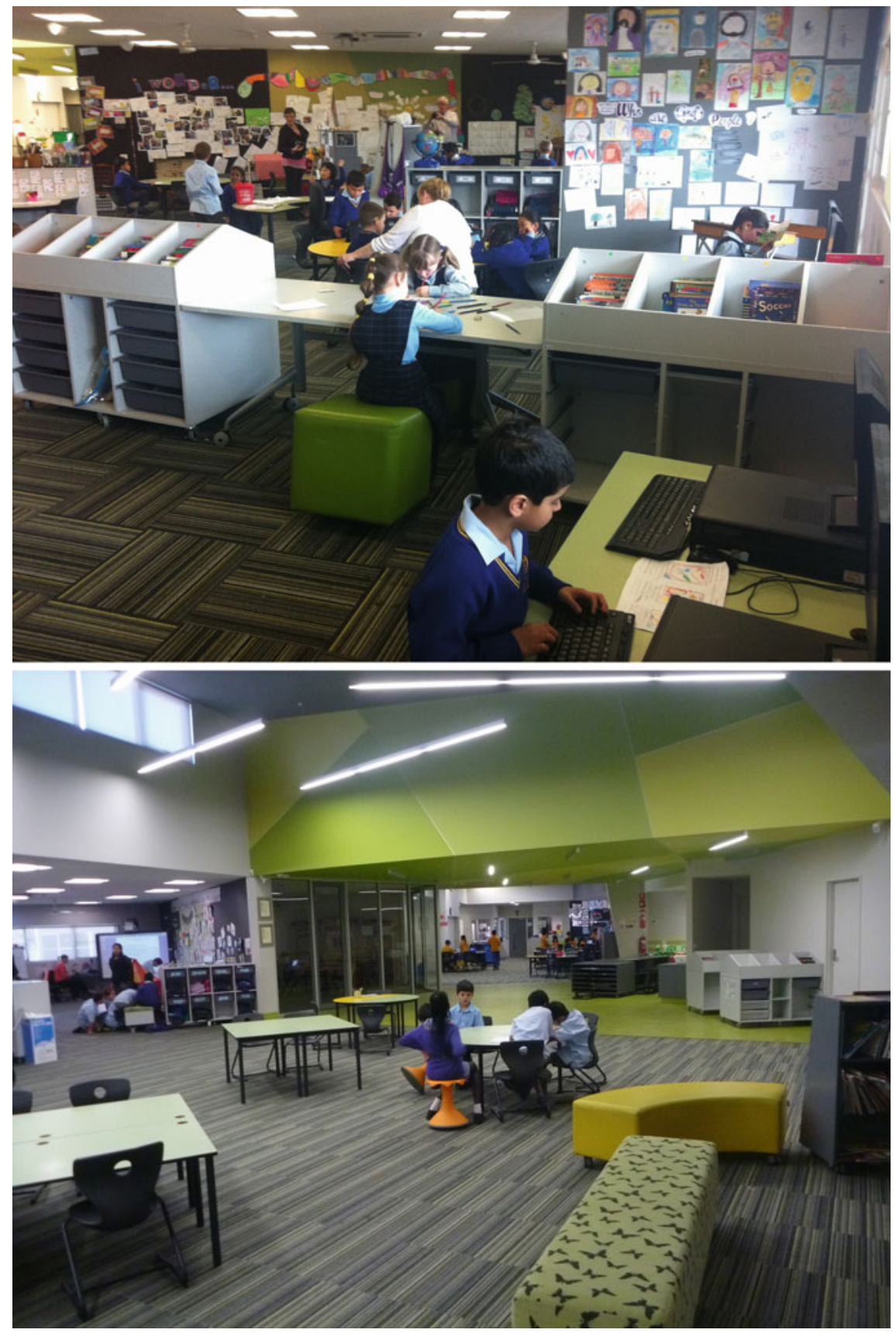

Fig. 1 Innovative Learning Environment in an Australian primary school 
the notion that communication in open-plan space is inhibited by unwanted noise. Collectively this highlights the fundamental importance of evaluating innovative learning environments ILEs to ensure that they offer enhanced opportunity for inclusion and that researchers are able to define determinants and affordances required for successful habitation.

\section{Inclusiveness of the Innovative Learning Environment}

It is widely recognised that in mainstream learning environments there is a diverse range of students with a variety of learning potentials and abilities. The term 'mainstream' implies that students will need to adapt to fit into the majority culture, and inclusion signifies that the programme will make adaptions to fit the needs of all students in the classroom (Stinson \& Foster, 2000). In determining the elements in an ILE that enable inclusion, it is important to consider the quality of the student's experiences while accounting for opportunities that help or hinder participation. Kay asserts it is unfair and unproductive to expect students to meet new and higher expectations in twenty-first-century learning spaces if the supporting infrastructure is not there (as cited in Bellanca \& Brandt, 2010).

In a mixed method multiple case study research project involving three students with hearing difficulties in one ILE, an interdisciplinary approach using methods from acoustical engineering, audiology and social science research were employed to gain insight into the environment under investigation (Imms, Cleveland, \& Fisher, 2016). A key driver of this study was to understand what supporting infrastructure and affordances enabled communicative experiences of students with hearing difficulties in an open-plan environment.

The methodological approach aimed to explore issues of inclusion for students with hearing difficulties while accounting for the complexity of variables that impact the performance standard of the learning environment. Student experience is situated at the centre of the learning environment evaluation process. In this study Radcliffe's (2009) Pedagogy, Space, Technology Learning Environment Evaluation Framework was utilised as grounding for this research because it offers a simple framework that identifies patterns in what institutions are trying to achieve, the ways in which they do this, and how they evaluate success. The questions asked within the framework can be tailored to meet particular ways of doing work, and the process is one which is 'inherently self-documenting and aids the elicitation of lessons learned for future projects' (Radcliffe, 2009, p. 14). Complimenting this approach Brinkerhoff's (2005) Success Case Methodology that explores 'what works' in times of fast-paced change while accounting for the 'value-add' of learning. As a result of this emergent approach, the evidence collected assisted in identifying particular design, technological and pedagogical elements in the ILE, which impact the inclusion of students with hearing difficulties in ILE's. 


\section{Methods}

In this study, the ILE under investigation was an open-plan primary school and 3 students with diagnosed hearing difficulties were the cases. To begin, the building structure was tested to determine the acoustic performance, and how noise was mediated by the design affordances of classroom spaces and breakout areas. An affordance can be described as a quality of an object or an environment that allows an individual to perform an action (Gibson, 1977; Wright \& Parchoma, 2011). For instance, during noisy learning activities the wall structures were tested to determine if unwanted sounds were absorbed of if sound echoed and bounce off walls creating additional interference in accessing clear speech in the environment.

After determining the baseline acoustic performance of various spaces within the open-plan environment, the focus switched to collection of qualitative data using photo-elicitation and semi-structured interviews with the case study students. It was fundamentally important to establish the student's perceived level of inclusion, the quality of their experiences in the learning environment and their interpretation of such. This evidence was then triangulated against the acoustic data. Affordances are also properties of the system, as perceived by the user, that allow certain actions to be performed and which encourage specific types of behaviour (Cox et al., 2004). Affordances speak directly to the quality of an experience as a result of an action, and in doing so go beyond the current rhetoric of inclusive education policies that speak to the notion of reasonable adjustments (Disability Discrimination Act 1992, 1992; Disability Standards for Education 2005, 2005). Given the absence of research on inclusion of 'mainstreamed' students with hearing difficulties in open-plan ILEs, a multifaceted, multi-lens approach to data collection was taken to ensure reliability, validity and to mitigate researcher bias while evaluating student perceptions about the environment (Blackmore, Bateman, Loughlin, O’Mara, \& Aranda, 2011; Spencer \& Marschark, 2010).

The study focus was not on the hearing deficit of the student but rather on the students' experience in the ILE, and how the performance of the environment mediated inclusion of these students. As such further key research questions included:

- How are teachers planning the use of the environment to promote inclusion?

- How and in what ways is communication facilitated?

- What elements within the open-plan learning environment facilitate opportunity for participation in speaking and listening? 
In addition, the subsidiary aims of the study were to:

- Investigate the environment's technology and acoustical affordances and properties to determined their influences on inclusion and subsequently what affordances should be adopted as best practice initiatives.

- Investigate the teachers' and students' preferential use of places to communicate within the learning space to determine how innovative learning environments could be best utilised for optimal access to speaking and listening activities.

This study and the approach taken highlighted the fundamental purpose of coming together in a face-to-face space to learn, and draws attention to:

- The importance of an acoustic platform that enables opportunity for all to participate in speaking and listening activity.

- Student agency, the power to act and contribute to decisions about how best one might learn, and the environmental affordances that enable opportunity and success.

The emergent methodological approach enabled the capture of convergent and divergent thinking regarding the intersection of the elements of pedagogy, space and technology in the innovative environment, and the subsequent impact upon inclusion of students with hearing difficulties.

\section{Acoustic Findings}

Acoustic quantitative data is fundamentally important data that corroborates or explains what helps or hinders inclusion in communicative opportunities for the inhabitants of ILEs. In a mixed methods evaluation design, substantive inferences about the affordances of the environment are made and further interrogated using qualitative methods such as semi-structured interviews, focus groups, structured observations and photo-elicitation (Moss, 2008).

In this study a noise logger, an acoustical measurement tool, logged the average equivalent background noise measured in decibels over time within a set position in the ILE. This measure gave an indication of the typical background noise levels that students and teachers commonly experienced within this space over time. Noise was logged at an average of 75 decibels $(\mathrm{dB})$. It is reported that for intelligible speech to be heard by students with normal hearing abilities at a distance of 2-3 $\mathrm{m}$ from the presenter, background noise should not exceed $55 \mathrm{~dB}$ (Flexer, Smaldino, \& Crandell, 2005) and the voice of the presenter be $20 \mathrm{~dB}$ above background noise. Effectively a teacher would have to shout at $95 \mathrm{~dB}$ for this condition to be met (Fig. 2).

Reverberation times were recorded; these are a simple indication of how the building performs in terms of absorbing sound reflections or echoes. The breakout spaces in the ILE recorded between 0.4 standards $>0.6$ RT (reverberation time), satisfying recommended RT for 'classrooms' (AAAC, 2010). However, the adjacent open-plan common learning area recorded 1.1 RT, far exceeding recommendations. 


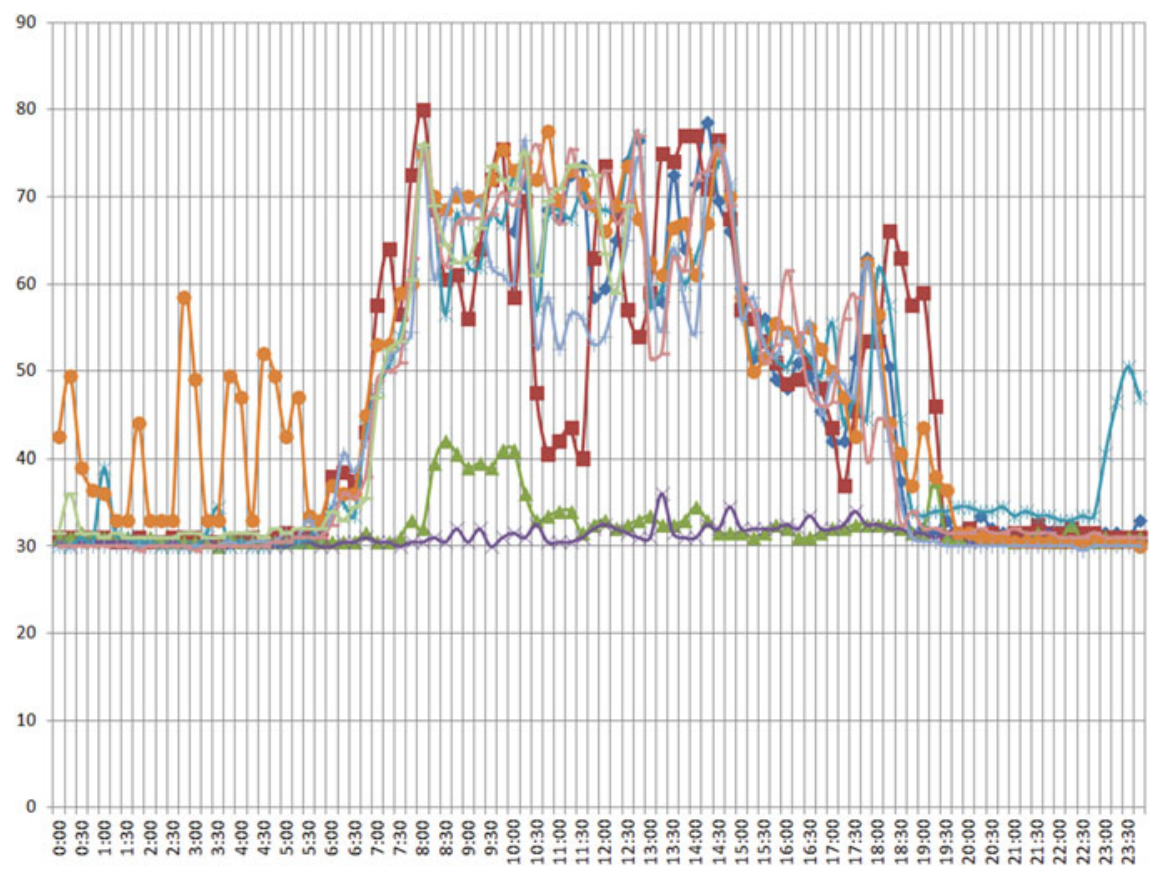

Fig. 2 Graph 1 of noise logger data, average noise level reading 75 dBA, administered by Marshal Day Acoustics Pty Ltd

This noise often spilt into the breakout zones and was reported as 'an annoying source of disruption' by a case study student, this sentiment was repeated by other students and teachers throughout the study.

Finally, innovative equipment was administered by an acoustical engineer that captured the clarity (C50) of speech sounds at points within the learning environment. These measurements are depicted as an Iris plot ${ }^{\mathrm{TM}}$ in graph 2 (Fig. 3) and graph 3 (Fig. 4), which showed the most direct signal from the source to receiver (red spike) and interfering sound reflections (blue and green spikes). This data enabled the identification of optimal positions for presenting when addressing students in speaking and listening activities in the ILE.

Graphs 2 and 3 show a comparison of speech clarity C50 in 2 different locations depicted visually by Marshall Day Iris plot ${ }^{\mathrm{TM}}$. This data is fundamental to the formulation of Standards that enable equitable access for those with hearing difficulties in buildings such as public meeting spaces, and in particular education facilities. For example, the Association of Australian Acoustical Consultants (AAAC) recommend the following acoustical design conditions for classrooms, outlined in Table 1, be adopted as a Standard for achieving hearing accessibility to clear speech in classrooms. 

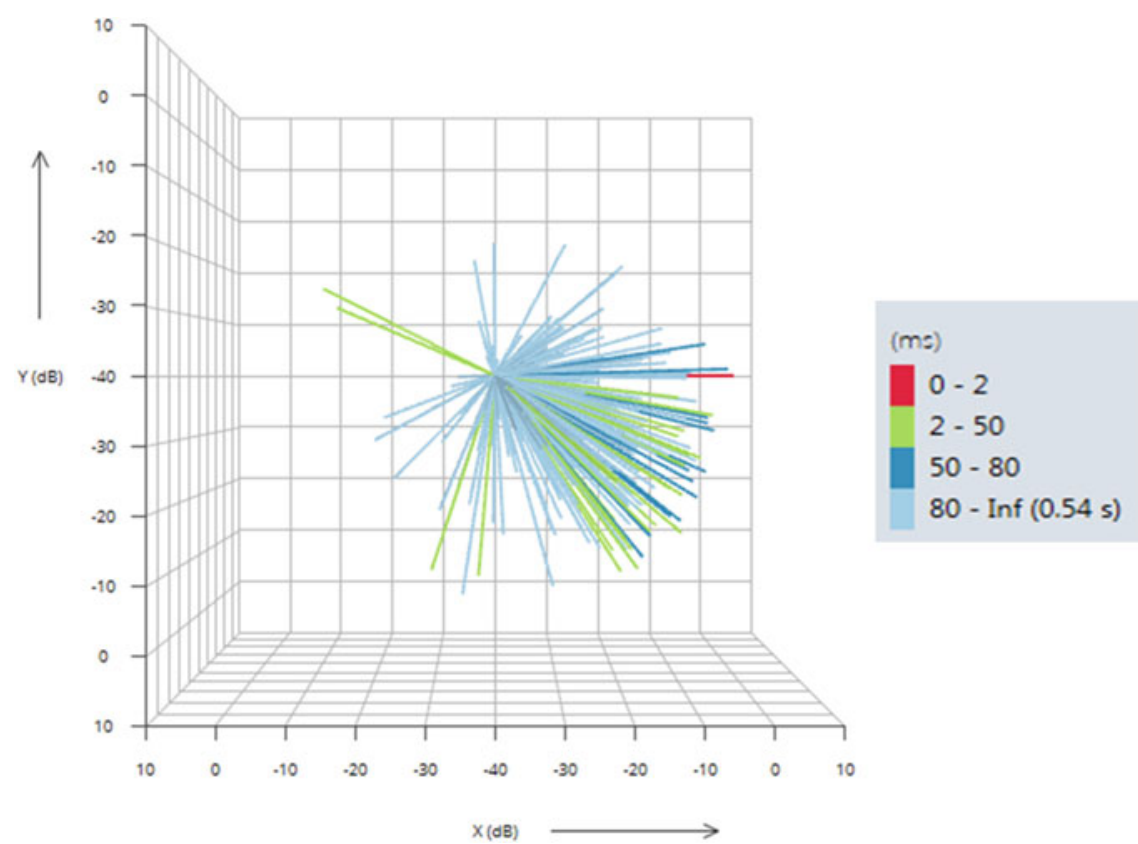

Fig. 3 Graph 2 of poor speech clarity

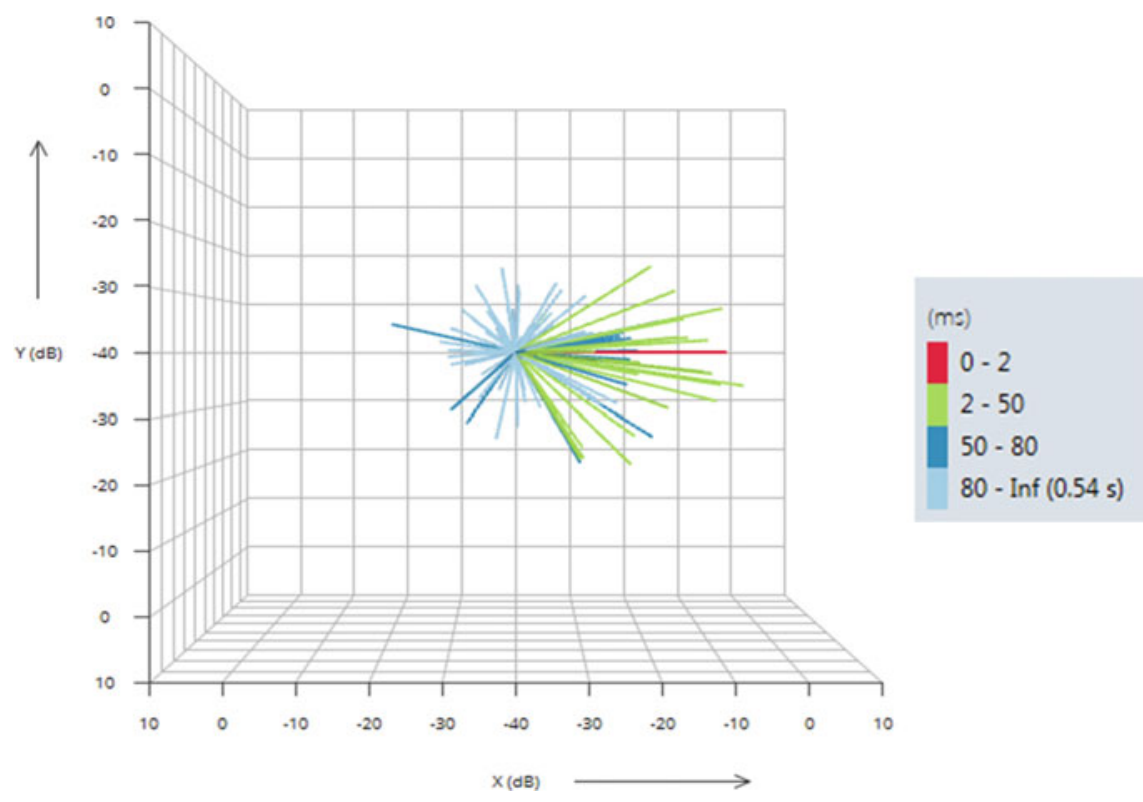

Fig. 4 Graph 3 of good speech clarity 
Table 1 Guideline for educational facilities acoustics (AAAC, 2010)

Recommended classroom acoustical design conditions Association of Australian Acoustical Consultants Guideline for Educational Facilities Acoustics (2010)

- A spoken voice level at least $15 \mathrm{~dB}$ above the background noise level throughout the room;

- Background noise levels of 30-40 dBA, or less when unoccupied;

- Overall sound levels (consisting of teaching voice and student voice) no greater than 65-70 dBA throughout the room;

- Sound-absorbing materials, placed to minimise reverberation to less than $0.4 \mathrm{~s}$ in primary teaching spaces and $0.6 \mathrm{~s}$ in secondary teaching spaces, including at least $40 \%$ absorptive treatment on the ceiling;

- A Speech Transmission Index STI $>0.6$ in open-plan teaching and study spaces

For the further case of students with special hearing requirements the following acoustical design conditions should also be satisfied

- Reverberation time of $0.4 \mathrm{~s}$ or less

- Signal to noise ratio of greater than $20 \mathrm{~dB}$

\section{Student Voice Findings}

In this study, the acoustic data provided a context to better understand student voice gained through the qualitative case study approach. While the noise logger demonstrated excessive noise present at a specific location, it was found that in particular locations the teachers voice was clearer. This was attributed to the shape, configuration and structural elements in the room, such as a noise control acoustic rated wall panelling, lower ceiling height with acoustic rated tiles, and carpet and soft furnishings that dampened noise. When students were given agency, the power to act, (Van Lier, 2008) they intuitively positioned themselves in the spaces that had been empirically identified as having good acoustic affordance, and supported greater accessibility to clear speech. Corroborating this finding in semi-structured interviews using photo-elicitation, the students revealed that these spaces were their favourite spaces to retreat to when given freedom to do so, in particular during independent learning times.

When excessive noise was generated by surrounding student and teacher activity, technology such as iPads and interactive whiteboards acted as communication tools providing visual clues and prompts. This enhanced the case study students' accessibility to learning. While these tools were not a substitute for speech, they provided a bridge that enabled students an avenue to independently interpret the requirements of a learning activity. Technology devices also provided a level of anxiety reduction by engaging the case study students in learning via multi-modal pathways. 'Special' access to technology tools gave comfort to the students with hearing difficulties who at times completed tasks before other students not identified as having a hearing difficulty. While technological affordances were present and in abundance in the ILE, student use was restricted by the teachers who tended to deploy tech tools as 'an additional learning activity' rather than an embedded part of learning. Similarly, the ILE was fitted with a sound-field system, consisting of a number of distributed low-level 
amplification speakers, a teacher worn microphone with a student pass around handheld microphone. The sound-field speakers lifted the voice of the presenter above the background noise, overcoming the distance from the teacher-to-background noise ratio for students. When the sound-field system was in use noise generation momentarily abated in the immediate area as well as co-located spaces. This Lombard effect, the involuntary tendency of speakers to increase their vocal effort when speaking in loud noise to enhance the audibility, was resolved by the sound-field system. Teachers no longer shouted and competed with each other to be heard when using the system. While all teachers acknowledged the benefits of the use of such technology, it was spasmodically used. This frustrated one of the case study students who took it upon herself to constantly remind teachers to use it.

Developing a culture of trust in working with others was identified by the case study students as fundamental to their inclusion in the ILE. Students said when teachers trusted their judgement and supported their choice to move to particular spaces and work with others, they felt more included because they could understand speech and the nature of the learning activity more clearly. The teachers however said they were unaware that this example of student agency was an important factor for including the case study students in various activities. There were many times, particularly when noise escalated, that student agency was taken away and didactic teaching prevailed. At these times, the case study students could not access their learning buddy, reposition themselves to acoustically supportive positions or use technology to bridge the learning activity. Noise appeared to be the trigger for reverting to didactic teacher-centred practices. Teachers reported feelings of exhaustion after days of working in noisy spaces, justifying decisions to limit collaborative activities in the open-plan area and retreat to the breakout areas for quieter teacher-directed learning activities, where they felt they could have an impact on control noise.

\section{Discussion, Evaluating Inclusiveness of Innovative Learning Environments}

Today more than ever in a student's learning journey it is critical that all have opportunity to participate and develop the ability to collaborate, connect to others, creatively problem solve and transfer content knowledge to many contexts. Highly effective communication skills are fundamental for participation in lifelong education and future job markets. Given this, it can be said that traditional student success measures such as student academic achievement data may not capture the breadth of 'student success' in an ILE. For example, an individual student may make significant gains in terms of progress even though the student may be below or just reaching bench-mark standards.

Deployment of effective design affordances in ILE's involves the process of collectively translating ideas and inventions into physical, technological and pedagogical services that create 'value'. The concept of changing learning landscapes is not 
new, however evidencing the connection between learning environment and 'learner success' is relatively emergent in the research literature (Imms et al., 2016). 'Value' is dependent upon effectively addressing individual learner preferences and styles such that all have an opportunity to participate, 'including' students with hearing difficulties. Given this, the validity of the 'value-add' of design affordances might be considered in-part the physical and technological attributes of a learning space that prompt specific advantageous learning behaviours observable in a research setting; for example, active participation in face-to-face communicative experiences in an ILE. Such behaviours are observed and affirmed through relevant response and interaction to conversations. However, when accessibility to intelligible speech is challenged behaviours such as withdrawal and distraction from key conversations may be observed (Stake, 1995; Moss, 2008). When this occurs, learning becomes less inclusive and opportunity to participate may momentarily cease unless an alternative learning activity is offered. While protagonists of social science research methodology may argue various mitigating factors contribute to disengagement, corroborating acoustical data support the inference that a poor acoustic platform is a key element excluding students from active participation in face-to-face learning activity such as collaborative tasks reliant on verbal communicative experiences (Howard, Munro, \& Plack, 2010).

In this study when student agency was given, self-advocacy and self-regulation mechanisms were exhibited by students, i.e. the students explored their environment, finding spaces, places and multi-modal platforms that supported their learning, it was in such times that the aspirations of twenty-first-century skill development were observed. Students and their learning buddies co-constructed knowledge communicating through multi-modal pathways not reliant on the transmission of speech but rather through text, pictures, model materials and technology devices.

Informed student voice relates to the notion that as key inhabitant's students are well positioned to provide feedback on the spatial attributes and affordances that enrich their learning and the elements that enable inclusion and participation (Van Lier, 2008, Gibson, 1977; Pruyn, 1999). As informed student voice emerges, it can be used to cultivate design affordances and pedagogic and operational practices that enhance inclusion through enabling activation of diverse learning styles and preferences in the ILE.

\section{Conclusion}

As more research studies emerge on ILE's researchers note that particular space designs or typologies elicit particular human behaviours and responses to participation in learning activities. What is known is that collaborative learning activities generate noise and noise is a factor that impacts communicative experiences (Munro 2011). By varying the spatial form, layout of a room and incorporation of acoustic attenuation and technological affordances noise can be controlled such that it minimises negative impacts on learning efficacy (Guardino \& Anita, 2012). 

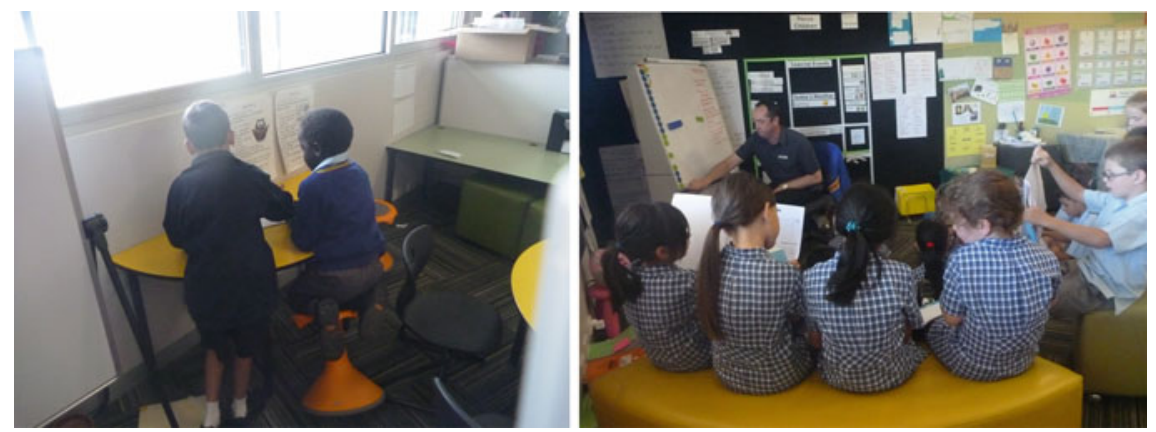

Fig. 5 Example of working with a trusted other in a 'Nook'

For example, the discovery of the value of 'acoustic nooks' (sensory reduction zones within the learning environment that mediated noise) and 'the trusted other' (a person the case study students identified as a good peer who could aid their learning) were identified as affordances of the ILE that enabled inclusion of students. See Fig. 5.

Rigorous evaluation of ILEs presents a plethora of opportunity for many stakeholders invested in enhancing educational outcomes for all students. Design principles associated with inclusive fit-for-purpose speaking and listening environments have yet to be broadly identified in the context of education building infrastructure. While many studies have demonstrated that excessive noise has detrimental effects on learning, assumptions regarding open-plan learning environments based on past research may not apply in these technology rich spaces that employed the use of innovative acoustic materials, design elements and student-centred pedagogies. Interdisciplinary approaches to evaluation may assist in closing the gap between students with and without learning disabilities and differences. This is because these types of methods critique the interplay between numerous elements acting in synergy. Knowing how to balance particular evidence-based elements leads to enhanced inclusion and greater opportunity for to student access to learning.

This study used a multi-lens approach that valued collaboration and interdisciplinary thinking, which sits within the philosophical framework of twenty-firstcentury learning environments. Broad approaches such as those described above are supported by Kalikoff who put the case for a mosaic approach that involved the implementation of a series of textured and complementary evaluation strategies that aimed to provide reliable and detailed information about what was being accomplished in the context of the environment under investigation (Kalikoff, 2001).

While it was found that particular identified affordances enhanced inclusion of students with hearing difficulties in the ILE, there were many instances where students were inadvertently excluded. There is an ongoing imperative to identify and embed design principles for learning spaces that account for high-quality noise control and professional learning for teachers, administrators and designers involved in developing and operationalising such spaces. As such, return on investment of rigorous evaluation of learning spaces is validated by assurance that identified design 
principles lead to development of exemplar fit-for-purpose learning environments that offer opportunity for all students, in particular those with hearing difficulties to be actively and successfully included in learning.

Acknowledgements Data utilised in this research was obtained in adherence to the required ethical protocol of the author's host institution. All images and diagrams are the property of the author, or the author has obtained consent to use them from the appropriate copyright owner.

\section{References}

Anderson, K. (2001). Kids in noisy classrooms: What does the research really say? Journal of Educational Audiology, 9, 21-33.

Association of Australian Acoustical Consultants Guideline for Educational Facilities Acoustics (2010, September). Retrieved from www.aaac.org.au8/8/2017.

Australian Hearing. (2013). 2012-2013 annual report. NSW, Australia: Australian Hearing.

Bellanca, J., \& Brandt, R. (2010). 21 st century skills; Rethinking how students learn. Bloomington, IN: Solution Tree Press.

Blackmore, J., Bateman, D., Loughlin, J., O'Mara, J., \& Aranda, G. (2011). Research into the connection between the built learning spaces and student outcomes. Melbourne: Department of Education and Early Childhood Development.

Brinkerhoff, R. (2005). The success case method: A strategic evaluation approach to increasing the value and effect of training. Advances in Developing Human Resources, 7, 86-101. https://doi. org/10.1177/1523422304272172.

Brown, S., \& Eisenhardt, K. (1997). The art of continuous change: Linking complexity theory and time-Pace evolution in relentlessly shifting organizations. Administrative Science Quarterly, $42,1-34$.

Byrnes, L. (2011). Listening to the voices of students with disability: What do adolescents with hearing loss think about different educational settings? Deafness and Education International, 13(2).

Clark, C., \& Sorqvist, P. (2012). A 3 year update on the influence of noise on performance and behaviour. Noise \& Health, 14(16), 292-296.

Cox, M., Webb, M., Abbott, C., Blakely, B., Beauchamp, T., \& Rhodes, V. (2004). ICT and pedagogy: A review of the research literature. A report to the DfES. Unknown Publisher.

Disability Discrimination Act 1992. (1992).

Disability Standards for Education 2005. (2005).

Flexer, C., Smaldino, J., \& Crandell, C. (2005). Sound field amplification applications to speech perception and classroom acoustics (2nd ed.). Canada: Thomson Demar Learning.

Gibson, J. (1977). The theory of affordances. In R. Shaw \& J. Bransford (Eds.), Perceiving, acting and knowing: Toward an ecological psychology. Oxford: Oxford University Press.

Glaser, B., \& Strauss, A. (1967). The discovery of grounded theory: Strategies for qualitative research. London: Weidenfeld and Nicholson.

Guardino, C., \& Antia, S. (2012). Modifying the classroom environment to increase engagement and decrease disruption with students who are deaf or hard of hearing. Journal of Deaf Studies and Deaf Education, 17(4), 518-533.

Howard, C., Munro, J., \& Plack, C. (2010). Listening effort at signal to noise ratios that are typical of the school classroom. International Journal of Audiology, 49, 928-932.

Imms, W., Cleveland, B., \& Fisher, K. (2016). Evaluating Learning Environments: Snapshots of emerging issues, methods and knowledge (W. Imms, B. Cleveland, K. Fisher, Eds.). Rotterdam: Sense Publishers. 
Kalikoff, B. (2001). From cohesion to collaboration: A mosaic approach to writing center. Writing Lab Newsletter, 26(1), 5-7.

Katte, M., Bergstroem, K., \& Lachmann, T. (2013). Does noise affect learning? A short review on noise effects on cognitive performance in children. Frontiers in Psychology, 4(578), 142.

Massie, R., \& Dillon, H. (2006). The impact of sound-field amplification in mainstream crosscultural classrooms: Part 1 Educational outcomes. Australian Journal of Education, 50(1), 62-77.

Moss, J. (2008). Researching education visually-digitally-spatially. Rotterdam, The Netherlands: Sense Publishers.

Munro, J. (2011). Teaching oral language building a firm foundation using ICPALER in the early primary years. Camberwell: ACER Press.

Pruyn, M. (1999). Discourse wars in Gotham-West, a Latino immigrant urban tale of resistance and agency. Boulder: Westview Press.

Radcliffe, D. (2009). A Pedagogy-Space-Technology (PST) framework for designing and evaluating learning spaces. In D. Radcliffe, H. Wilson, D. Powell, \& B. Tibbetts (Eds.), Learning spaces in higher education: Positive outcomes by design. Proceedings of the Next Generation Learning Spaces 2008 Colloquium (pp. 9-16). Brisbane, Australia: University of Queensland.

Rowe, K., \& Pollard, J. (2003). Auditory processing: Literacy, behaviour and classroom practice. ACQ: Acquiring Knowledge in Speech, Language and Hearing, 5(3), 134.

Sharma, M., Purdy, S., \& Kelly, A. (2009). Comorbidity of auditory processing, language and reading disorders. Journal of Speech and Hearing Research, 52, 706-722.

Shield, B., Greenland, E., \& Dockrell, J. (2010). Noise in open plan classrooms in primary schools: A review. Noise \& Health, 12(49), 225-234.

Smaldino, J., \& Flexer, C. (2012). Handbook of acoustic accessibility: Best practices for listening, learning and literacy in the classroom. New York, NY: Thieme.

Snow, P. C., \& Powell, B. C. (2008). Oral language competence, social skills and high risk boys: What are juvenile offenders trying to tell us? Children and Society, 22, 16-28.

Spencer, P., \& Marschark, M. (2010). Evidence-based practice in educating deaf and hard-of hearing students. Professional perspectives on deafness: Evidence and applications. New York, NY: Oxford University Press.

Stake, R. (1995). The art of case study research. London: Sage.

Stinson, M. S., \& Foster, S. (2000). Socialization of deaf children and youths in school. In K. P. Meadow-Orlans, P. E. Spencer, C. Erting, \& M. Marschark (Eds.), The deaf child in the family and at school: Essays in honor of Kathryn P. Meadow-Orlans (pp. 191-209). Mahwah, NJ: Lawrence Erlbaum Associates.

Vosganoff, D., Paatsch, L., \& Toe, D. (2011). The mathematical and science skills of students who are deaf or hard of hearing educated in inclusive settings. Deafness and Education International, 13(2), 70-88.

Wright, S., \& Parchoma, G. (2011). Technologies for learning? An actor-network theory critique of 'affordances' in research on mobile learning. Research in Learning Technology, 19(3), 247-258.

van Lier, L. (2008). Agency in the classroom. In Lantolf, J. P. \& Poehner, M. E. (Eds.) (2008), Sociocultural theory and the teaching of second languages. London: Equinox. 
Open Access This chapter is licensed under the terms of the Creative Commons Attribution 4.0 International License (http://creativecommons.org/licenses/by/4.0/), which permits use, sharing, adaptation, distribution and reproduction in any medium or format, as long as you give appropriate credit to the original author(s) and the source, provide a link to the Creative Commons license and indicate if changes were made.

The images or other third party material in this chapter are included in the chapter's Creative Commons license, unless indicated otherwise in a credit line to the material. If material is not included in the chapter's Creative Commons license and your intended use is not permitted by statutory regulation or exceeds the permitted use, you will need to obtain permission directly from the copyright holder.

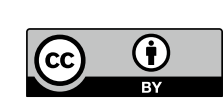

